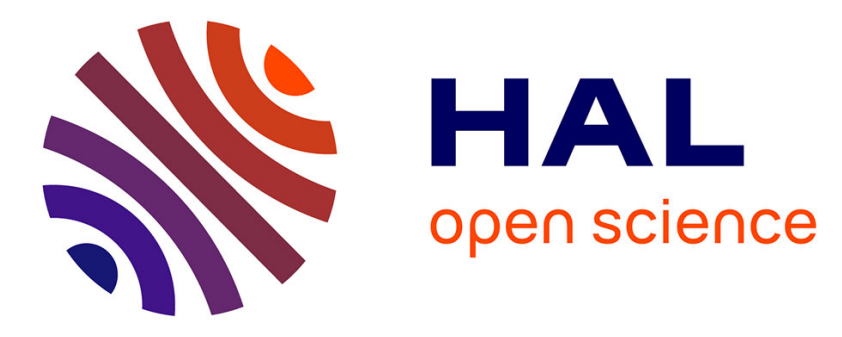

\title{
Mechanical response and energy stored during deformation of crystallizing TPU
}

A. Lachhab, Eric Robin, Jean-Benoit Le Cam, F. Mortier, Y. Tirel, F. Canévet

\section{> To cite this version:}

A. Lachhab, Eric Robin, Jean-Benoit Le Cam, F. Mortier, Y. Tirel, et al.. Mechanical response and energy stored during deformation of crystallizing TPU. SEM Annual Conference and Exposition on Experimental and Applied Mechanics, 2018, Jun 2018, Greenville, United States. pp.51-56, 10.1007/978-3-319-95074-7_10. hal-02161139

\section{HAL Id: hal-02161139 \\ https://hal-univ-rennes1.archives-ouvertes.fr/hal-02161139}

Submitted on 10 May 2020

HAL is a multi-disciplinary open access archive for the deposit and dissemination of scientific research documents, whether they are published or not. The documents may come from teaching and research institutions in France or abroad, or from public or private research centers.
L'archive ouverte pluridisciplinaire HAL, est destinée au dépôt et à la diffusion de documents scientifiques de niveau recherche, publiés ou non, émanant des établissements d'enseignement et de recherche français ou étrangers, des laboratoires publics ou privés.

\section{(c)(1)}

Distributed under a Creative Commons Attribution| 4.0 International License 


\title{
Mechanical Response and Energy Stored During Deformation of Crystallizing TPU
}

\author{
Abdelmonem Lachhab, Eric Robin, Jean-Benoît Le Cam, Frédéric Mortier, Yvon Tirel, and Frédéric Canévet
}

\begin{abstract}
The present study investigates the thermomechanical behavior of closed-cell TPU foams. The effects of the density and the loading conditions on the softening, the residual strain and the hysteresis have first been characterized. The thermal responses exhibit numerous particularities. First, a threshold effect in terms of the density on the self-heating has been highlighted. Second, entropic effects are strongly weighted by energetic effects (internal energy variations) during the deformation. Typical changes in the thermal response highlight that SIC and crystallite melting occur during the deformation. The characteristic stretches of this phenomenon evolve with the maximum stretch applied. The lower the density, the lower the crystallinity. In the second part of this study, a complete energy balance is carried out during cyclic deformation of compact and foamed crystallizing TPUs. Results show that viscosity is not the only phenomenon involved in the hysteresis loop formation: a significant part of the mechanical energy brought is not dissipated into heat and is stored by the material when the material changes its microstructure, typically when it is crystallizing. Some of this energy is released during unloading, when melting occurs, but with a different rate, which contributes to the hysteresis loop. The part of the mechanical energy stored by the material has been quantified to investigate the effects of the loading rate and the void volume fraction on the energetic response of TPU. These effects cannot be predicted from the mechanical responses and the present study provides therefore information of importance to better understand and model the effects of the density and the loading conditions on the thermomechanical behavior of closed-cell TPU foams.
\end{abstract}

Keywords TPU foam · Intrinsic dissipation · Energy stored · Strain-induced crystallization · Infrared thermography

\subsection{Introduction}

The thermoplastic polyurethanes (TPUs) are subjected to many anelastic phenomena such as mechanical hysteresis, residual stretch and softening [1-6], which strongly depend on the material formulation. When foamed, TPU becomes more deformable and are still dissipative [7-10]. The energy dissipation capacity of TPU is classically measured as the mechanical hysteresis area, but no study investigates the physical origin of this dissipation, while three phenomena could be responsible for this mechanical hysteresis: the intrinsic dissipation $\left(\mathrm{d}_{1}\right)$, due to internal friction and/or damage, which leads to selfheating; the thermal dissipation $\left(\mathrm{d}_{2}\right)$ and the part of the mechanical energy used by the material to change its microstructure ( $W_{\text {structure }}$, see for instance recent studies on polyurea [11], natural rubber [12] and nitrile rubber [13].

Such analysis is classically carried out in metallic materials [14-17]. Polymers have then benefited from this approach [18-21]. Concerning elastomers, only two recent studies by Le Cam and co-workers investigate the energetic behavior and the energy storage during deformation $[12,13]$. To further discuss on the relative contribution of the energy stored in the hysteresis loop of rubbers, they proposed a ratio $\gamma_{s e}$, written in terms of energies over one mechanical cycle as follows:

\author{
A. Lachhab \\ Univ Rennes, CNRS, IPR (Institute de Physique de Rennes) - UMR 6251, Rennes, France \\ LC-DRIME, Joint Research Laboratory, Cooper Standard - Institut de Physique UMR 6251, Rennes Cedex, France \\ Cooper Standard France, Rennes, France \\ E. Robin · J. -B. Le Cam $(\bowtie)$ \\ Univ Rennes, CNRS, IPR (Institute de Physique de Rennes) - UMR 6251, Rennes, France \\ LC-DRIME, Joint Research Laboratory, Cooper Standard - Institut de Physique UMR 6251, Rennes Cedex, France \\ e-mail: jean-benoit.lecam@univ-rennes1.fr \\ F. Mortier · Y. Tirel · F. Canévet \\ Cooper Standard France, Rennes, France
}




$$
\gamma_{\text {se }}=\frac{W_{\text {stored }}^{\text {cycle }}}{W_{\text {hyst }}^{\text {cycle }}}
$$

$W_{\text {stored }}^{\text {cycle }}$ is the energy stored over one cycle, $W_{\text {hyst }}^{\text {cycle }}$ is the energy of the hysteresis loop.

The physical meaning of this ratio is different from the Taylor-Quinney coefficient, since it is not measured from a latent energy remaining after cold working: the energy stored in the elastomer network can be released. In the present work, a complete energy balance is carried out in order to determine the effects of the loading conditions and the void volume fraction on the energetic behavior of compact and foamed TPUs. Section 10.2 presents the thermodynamic framework. Section 10.3 sums up the technique used to elaborate the samples, the loading conditions and the thermal measurement during the mechanical tests. Section 10.4 gives the results. Concluding remarks close the paper.

\subsection{Thermodynamical Framework}

\subsubsection{Total Strain Energy Density and Hysteresis Loop}

The strain energy density $W_{\text {strain }}\left(\right.$ in $\mathrm{J} / \mathrm{m}^{3}$ ) is the energy brought mechanically to deform the material:

$$
W_{\text {strain }}^{\text {load }}=\int_{\text {load }} \pi d \lambda \text { and } W_{\text {strain }}^{\text {unload }}=\int_{\text {unload }} \pi d \lambda
$$

$\lambda$ is the stretch defined as the ratio of the current length over the initial one. $\pi$ is the nominal stress, defined as the force per unit of initial (undeformed) surface. If a hysteresis loop forms, the mechanical energy dissipated over one cycle $W_{h y s t}^{c y c l e}$ is defined as follows:

$$
W_{\text {hyst }}^{\text {cycle }}=W_{\text {strain }}^{\text {load }}-W_{\text {strain }}^{\text {unload }}
$$

From this energy, a quantity $P_{\text {hyst }}^{\text {cycle }}$ is calculated in $\mathrm{W} / \mathrm{m}^{3}$. It is obtained by dividing $W_{\text {hyst }}^{\text {cycle }}$ by the cycle duration.

\subsubsection{Heat Power Densities}

The homogeneous heat power density field $s$ obtained during uniaxial tensile loadings writes as follows [22]:

$$
s=\rho C\left(\dot{\theta}+\frac{\theta}{\tau}\right)
$$

where $\theta$ denotes the temperature variation $\left(T-T_{r e f}\right)$ with respect to the equilibrium temperature $T_{r e f}$ in the undeformed state. In the present case, $T_{\text {ref }}$ is constant and equal to the ambient temperature, which was constant during the tests. $\tau$ can be easily identified from a natural return to room temperature. Further details are provided in [23]. The heat power density can be divided into two terms that differ in nature: the intrinsic dissipation $\mathrm{d}_{1}$ and the thermomechanical couplings stmc. Their integration with respect to time over one cycle is null. Therefore, the temporal integration of Eq. 10.4 over one mechanical cycle provides the energy density due to intrinsic dissipation $W_{\text {int } \text { rinsic }}^{c y}$ :

$$
W_{\text {int } \text { rinsic }}^{\text {cycle }}=\int_{\text {cycle }}\left(s_{t m c}+d_{1}\right)=\int_{\text {cycle }} d_{1} d t
$$

$W_{\text {int } \text { rinsic }}^{\text {cycle }}$ is divided by the time duration to obtain the energy rate $P_{d_{1}}$ due to intrinsic dissipation. 


\subsubsection{Energy Balance}

The energy balance consists in comparing the energy contained in the mechanical hysteresis $W_{\text {hyst }}^{\text {cycle }}$, more precisely $P_{\text {hyst }}^{\text {cycle }}$, with $P_{d_{1}}$. If the both quantities are equal for a given cycle, all the mechanical energy of the hysteresis loop is converted into heat. Else, it is necessary to distinguish the part of the mechanical energy converted into heat from the one stored by the material to change its microstructure. For that purpose, the ratio $\gamma_{s e}$ recently proposed by Le Cam and co-workers [13] is used.

\subsection{Experiments}

The material considered here is a TPU referred to as Irogran R A87H4615 TPU marketed by the Huntsman corporation (The Woodlands, Texas, USA). The TPU is mixed with carbon dioxide in its supercritical state during injection, in order to form cells and to significantly decrease its density. The forming process is more precisely described in [6,24]. The samples were obtained by cutting a bar with a water jet cutting device. Three densities were compared: $1.2,0.7$ and $0.5 \mathrm{~kg} / \mathrm{dm}^{3}$, the corresponding samples are denoted respectively $\mathrm{d}_{1.2}, \mathrm{~d}_{0.7}$ and $\mathrm{d}_{0.5}$ in the following. The density equal to 1.2 corresponds to the compact form. The sample geometry and the loading condition are given in Fig. 10.1.

Uniaxial tensile loadings were carried out with a 5543 Instron testing machine. Tests were performed under prescribed displacement. The signal shape was triangular to ensure a constant strain rate during loading and unloading.

\subsubsection{Thermal Measurement}

Temperature field measurements were performed using a FLIR X6540sc infrared camera. The acquisition frequency was set at $50 \mathrm{~Hz}$. The thermal resolution (NETD) was equal to $20 \mathrm{mK}$ at $25{ }^{\circ} \mathrm{C}$. The calibration of the camera detectors was performed with a black body using a Non-Uniformity Correction (NUC) procedure. Temperature measurement is performed at the specimen centre, by averaging the temperature in a small zone of $5 \times 5$ pixels at the centre of the sample. As the zone moves during the test, a suitable movement compensation technique enables us to track this zone during the test (see [25-27] for further information on this technique).
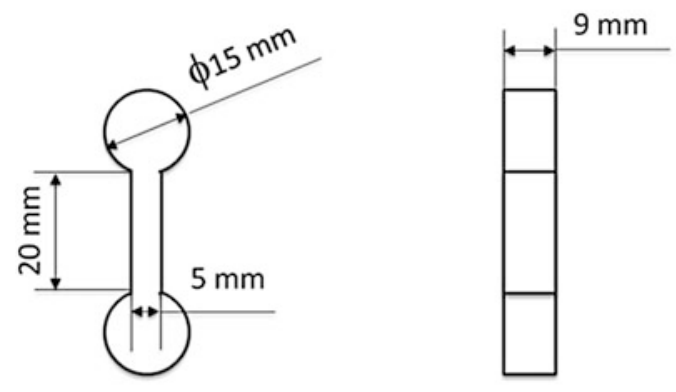

(a)

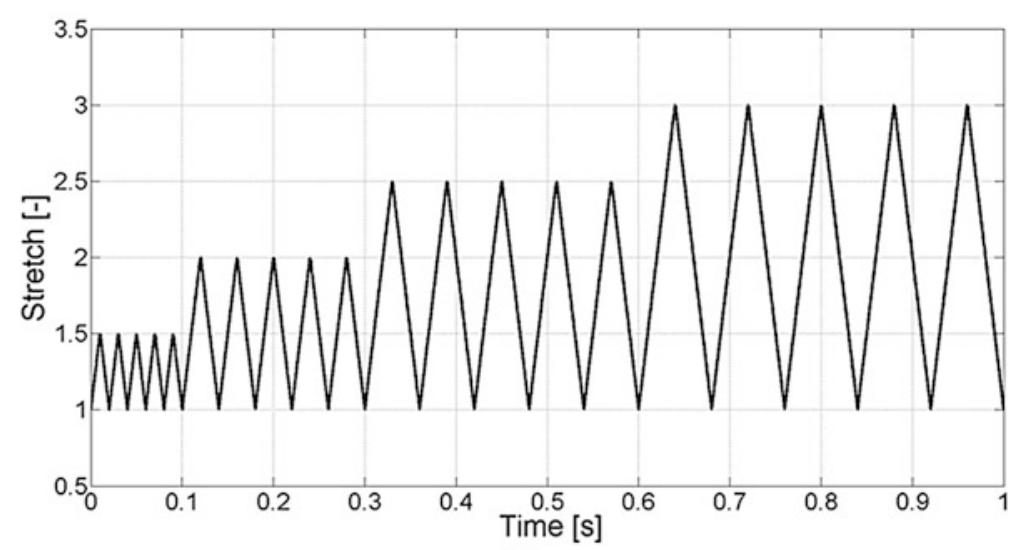

(b)

Fig. 10.1 (a) Sample geometry (b) loading conditions 


\subsection{Results and Discussion}

\subsubsection{Mechanical Responses}

The mechanical responses obtained are precisely detailed in [6] and is therefore not recalled here. The main results can be summed up as follows:

- decreasing the density leads to a decrease in the global stiffness and in the hysteresis area, slightly increases the residual stretch and does not affect significantly the stress softening;

- the loading rate has no significant influence on the stress softening, while it influences more the residual stretch and the hysteresis area. It should be noted that the loading rate does not affect significantly the stiffness, which is a less intuitive result that will be discussed in the following.

\subsubsection{Calorimetric Responses}

Parameter $\tau$ has been characterized for each test configuration and material tested and the corresponding heat power densities have been determined by applying Eq. 10.4. Results obtained are presented in Fig. 10.2a, b for the three densities tested at $\pm 100 \mathrm{~mm} / \mathrm{min}$ and $\pm 300 \mathrm{~mm} / \mathrm{min}$, respectively.

The heat power density increases when the TPU is stretched and decreases when the stress is released. The higher the density, the higher the maximum heat power densities produced. The material accommodates each time the maximum stretch is increased. Let us now consider the calorimetric response versus the stretch for the 3 densities at $\pm 300 \mathrm{~mm} / \mathrm{min}$, presented in Fig. 10.3. TPU $d_{1.2}$ is chosen as the reference one. For the first two sets of stretches applied $(\lambda=1.5$ and $\lambda=2)$, heat power densities are symmetrical with respect to the abscissa axis. Therefore, no significant intrinsic dissipation is produced. For sets at a maximum stretch superior to 2, a strong change in the curve slope is observed during the loading (at about $\lambda=2.1$ for the third set at $\lambda=2.5$ ). As the mechanical response does not exhibit such a singularity, this cannot be due to the effect of the entropic coupling. This strong increase in the heat production is analogue to what is observed in NR when crystallizes [12,

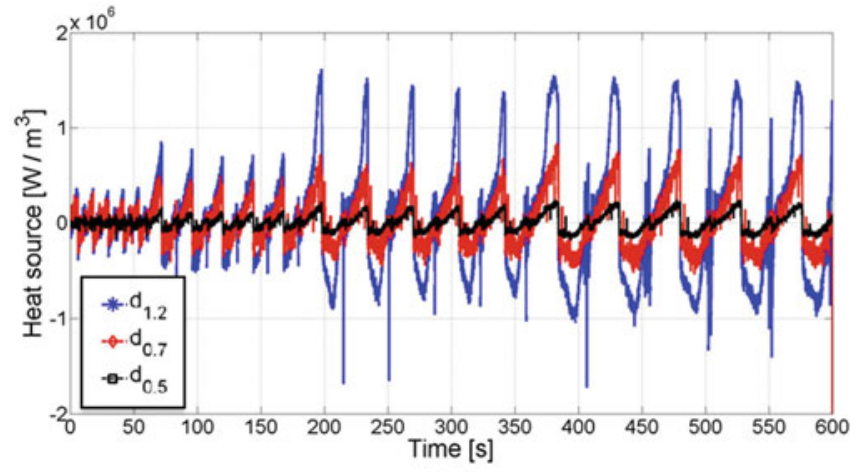

(a)

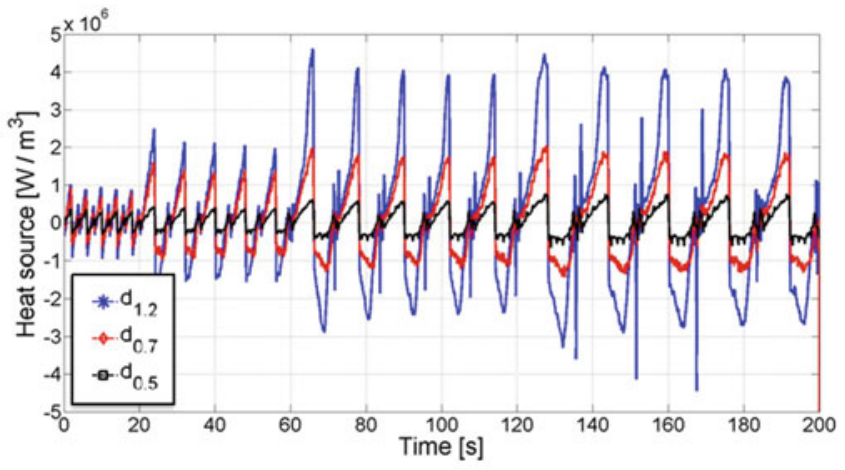

(b)

Fig. 10.2 Heat power density for the three densities. (a) $\pm 100 \mathrm{~mm} / \mathrm{min}$. (b) $\pm 300 \mathrm{~mm} / \mathrm{min}$

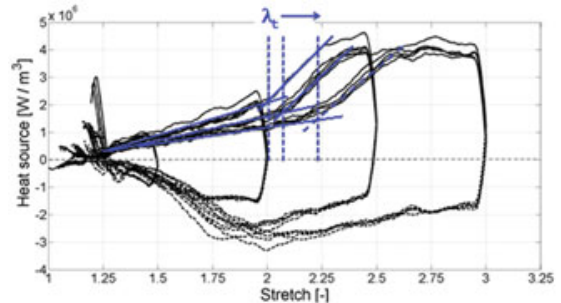

(a)

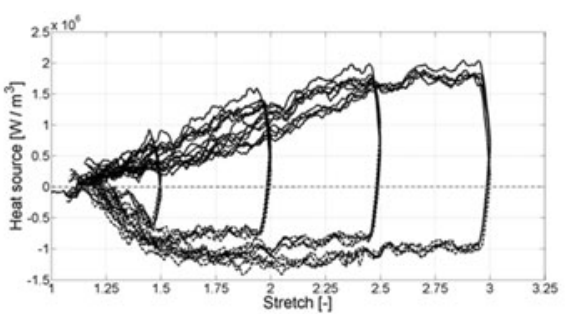

(b)

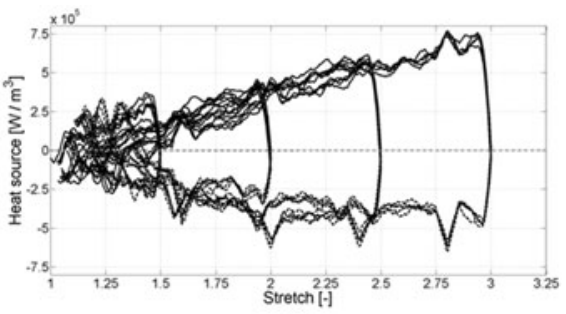

(c)

Fig. 10.3 Heat power density at $\pm 300 \mathrm{~mm} / \mathrm{min}$ for the three densities. (a) $\mathrm{d}_{1.2}$. (b) $\mathrm{d}_{0.7}$. (c) $\mathrm{d}_{0.5}$ 


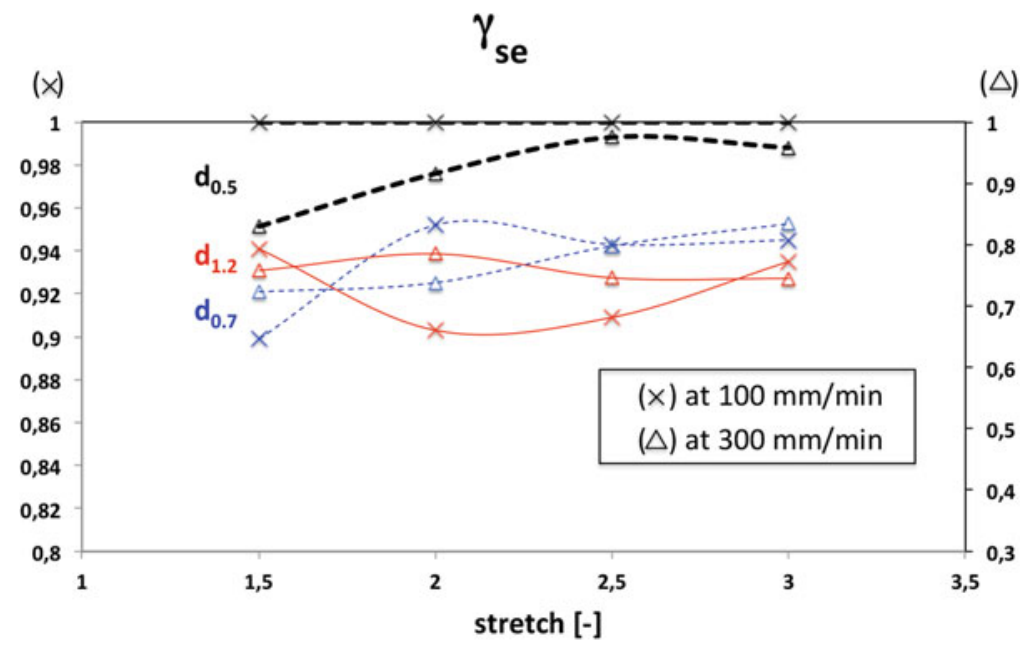

Fig. 10.4 $\gamma_{s e}$ in relation to the density, the loading rate and the stretch

23] and highlights that the present TPU is crystallizing under strain. The higher the maximum stretch applied, the higher the stretch at which the strong increase in the heat production is observed, and the higher the residual stretch. During unloading, a strong dissymmetry comparable to what is obtained in NR, is observed and strong heat absorption is observed at a stretch inferior to that at which SIC starts. The effects of the density and the loading rate will be more precisely detailed during the presentation.

\subsubsection{Energy Balance}

To further discuss on the energetic behavior and especially on physical origin of the mechanical hysteresis, Fig. 10.4 gives $\gamma_{s e}$ in relation to the density, the loading rate and the stretch. It should be noted that the calorific response is not stabilized from the second cycle, especially for results obtained samples $\mathrm{d}_{0.5}$ at $\pm 300 \mathrm{~mm} / \mathrm{min}$. In this case, $P_{d_{1}}$ tends to zero, which means that $\gamma_{s e}$ would be close to 1 whatever the stretch applied. Such a representation opens a new way to investigate the thermomechanical and energetic behaviour of elastomers.

\subsection{Conclusion}

The present study investigates the thermomechanical and calorific behavior of TPU foams. Complete energy balances have been carried out in order to highlight the physical origin of the hysteresis loop. Different densities were tested under cyclic uniaxial tension at different loading rates and sample densities, including the compact state, which ensures a relevant characterization of the effect of the cell volume fraction on the TPU's formulation used. The calorimetric response has shown that the material's elasticity is mainly entropic, but it uses mechanical energy brought to it to change its microstructure. This is in good agreement with measurements recently performed in a compact TPU in [11]. For samples of the highest density, viscous effects are found to increase with the loading rate, the density and the maximum stretch applied. This is not observed for sample of the lowest density, for which the intrinsic dissipation remains low. For the lowest density, no self-heating was observed, even when the loading rate was increased by a factor 3 . The fact that the material is able to store part of the mechanical energy probably explains why it is among the most resistant materials to the crack growth. Such a result is of importance when designing foamed TPU parts submitted to cyclic loadings.

Acknowledgements The authors thank the Cooper Standard France company for supporting this work and for fruitful discussions. The authors thank also the National Center for Scientific Research (MRCT-CNRS and MI-CNRS) and Rennes Metropole for supporting this work financially. 


\section{References}

1. Blundell, D., Eeckhaut, G., Fuller, W., Mahendrasingam, A., Martin, C.: Real time SAXS/stress strain studies of thermoplastic polyurethanes at large strains. Polymer. 43, 5197-5207 (2002)

2. Yeh, F., Hsiao, B., Sauer, B., Michael, S., Siesler, H.: In-situ studies of structure development during deformation of a segmented poly(urethaneurea) elastomer. Macromolecules. 36, 1940-1954 (2003)

3. Unsal, E., Yalcin, B., Yilgor, I., Yilgor, E., Cakmak, M.: Real time mechano-optical study on deformation behavior of ptmo/chdi-based polyetherurethanes under uniaxial extension. Polymer. 50, 4644-4655 (2009)

4. Bartolome, L., Aurrekoetxea, J., Urchegui, M.A., Tato, W.: The influences of deformation state and experimental conditions on inelastic behaviour of an extruded thermoplastic polyurethane elastomer. Mater. Des. 49, 974-980 (2013)

5. Qi, H., Boyce, M.: Stress-strain behavior of thermoplastic polyurethanes. Mech. Mater. 37, 81-839 (2005)

6. Lachhab, A., Robin, E., Le Cam, J.-B., Mortier, F., Tirel, Y., Canevet, F.: Thermomechanical analysis of closed-cell polymeric foams subjected to cyclic loading: anelasticity, self-heating and stressinduced crystallization. Polymer. 126, 19-28 (2017)

7. Blatz, P.J., Ko, W.L.: Application of finite elastic theory to the deformation of rubbery materials. Trans. Soc. Rheol. 6, 223-252 (1962)

8. Saint-Michel, F., Chazeau, L., Cavaillé, J.-Y., Chabert, E.: Mechanical properties of high density polyurethane foams: I. Effect of the density. Compos. Sci. Technol. 66, 2700-2708 (2006)

9. Alzoubi, M.F., Tanbour, E.Y., Al-Waked, R.: Compression and hysteresis curves of nonlinear polyurethane foams under different densities, strain rates and different environmental conditions. ASME. 9, 101-109 (2011)

10. Ugarte, L., Saralegi, A., Fernandez, R., Martin, L., Corcuera, M.A., Eceiza, A.: Flexible polyurethane foams based on $100 \%$ renewably sourced polyols. Ind. Crop. Prod. 62, 545-551 (2014)

11. Mott, P., Giller, C., Fragiadakis, D., Rosenberg, D., Roland, C.: Deformation of polyurea: where does the energy go? Polymer. 105, 227-233 (2016)

12. Le Cam, J.-B.: Energy storage due to strain-induced crystallization in natural rubber: the physical origin of the mechanical hysteresis. Polymer. 127, 166-173 (2017)

13. Loukil, M., Corvec, G., Robin, E., Miroir, M., Le Cam, J.-B., Garnier, P.: Stored energy accompanying cyclic deformation of filled rubber. Eur. Polym. J. 98, 448-455 (2018)

14. Chrysochoos, A.: Energy balance for elastic plastic deformation at finite strain (in french). Journal de Mecanique theorique et appliquee. 5, 589-614 (1985)

15. Mason, J., Rosakis, A., Ravichandran, G.: On the strain and strain rate dependence of the fraction of plastic work converted to heat: an experimental study using high speed infrared detectors and the kolsky bar. Mech. Mater. 17, 135-145 (1994)

16. Rittel, D.: On the conversion of plastic work to heat during high strain rate deformation of glassy polymers. Mech. Mater. 31, 131-139 (1999)

17. Oliferuk, W., Maj, M., Raniecki, B.: Experimental analysis of energy storage rate components during tensile deformation of polycrystals. Mater. Sci. Eng. A. 374, 77-81 (2004)

18. Rittel, D.: An investigation of the heat generated during cyclic loading of two glassy polymers. Part I: experimental. Mech. Mater. 32, 131-147 (2000)

19. Rittel, D., Rabin, Y.: An investigation of the heat generated during cyclic loading of two glassy polymers. Part II: thermal analysis. Mech. Mater. 32, 149-159 (2000)

20. Benaarbia, A., Chrysochoos, A., Robert, G.: Kinetics of stored and dissipated energies associated with cyclic loadings of dry polyamide 6.6 specimens. Polym. Test. 34, 155-167 (2014)

21. Benaarbia, A., Chrysochoos, A., Robert, G.: Influence of relative humidity and loading frequency on the PA6.6 thermomechanical cyclic behavior: Part II. Energy aspects. Polym. Test. 41, 92-98 (2015)

22. Chrysochoos, A.: Analyse du comportement des matériaux par thermographie infra rouge. Colloque Photomécanique. 95, 201-211 (1995)

23. Samaca Martinez, J.R., Le Cam, J.-B., Balandraud, X., Toussaint, E., Caillard, J.: Mechanisms of deformation in crystallizable natural rubber. Part 2: quantitative calorimetric analysis. Polymer. 54, 2727-2736 (2013)

24. Primel, A., Ferec, J., Ausias, G., Tirel, Y., Veille, J.-M., Grohens, Y.: Solubility and interfacial tension of thermoplastic polyurethane melt in super-critical carbon dioxide and nitrogen. J. Supercrit. Fluid. 122, 52-57 (2017)

25. Pottier, T., Moutrille, M.-P., Le Cam, J.-B., Balandraud, X., Grédiac, M.: Study on the use of motion compensation technique to determine heat power densities. Application to large deformations on cracked rubber specimens. Exp. Mech. 49, 561-574 (2009)

26. Toussaint, E., Balandraud, X., Le Cam, J.-B., Grediac, M.: Combining displacement, strain, temperature and heat power density fields to investigate the thermomechanical response of an elastomeric specimen subjected to large deformations. Polym. Test. 31, 916-925 (2012)

27. Samaca Martinez, J.R., Le Cam, J.-B., Balandraud, X., Toussaint, E., Caillard, J.: Mechanisms of deformation in crystallizable natural rubber. Part 1: thermal characterization. Polymer. 54, 2717-2726 (2013) 